\title{
Arterial Distensibility in Chronic Inflammatory Rheumatic Disorders
}

\author{
Mustafa Yildiz* \\ Department of Cardiology, Kartal Kosuyolu Yuksek Ihtisas Educational and Research Hospital (Kosuyolu Heart \\ Hospital), Istanbul, Turkey
}

\begin{abstract}
The pulse wave velocity (PWV), as an indicator of arterial distensibility, may play an important role in the stratification of patients based on the cardiovascular risk. PWV inversely correlates with arterial distensibility and relative arterial compliance. Decreased arterial distensibility alters arterial blood pressure and flow dynamics, and disturbes coronary perfusion. Systemic immune and inflammatory diseases, such as rheumatoid arthritis (RA) and systemic lupus erythematosus (SLE) are associated with increased morbidity and mortality, predominantly due to adverse cardiovascular events. Systemic inflammation in these disorders may alter arterial compliance and arterial distensibility and, through this effect, lead to accelerated atherosclerosis. We have demonstrated an increase in the carotid-femoral (aortic) PWV that is a technique in which large artery elasticity is assessed from analysis of the peripheral arterial waveform, in patients with chronic inflammatory conditions such as RA, SLE, familial Mediterranean fever (FMF), Wegener's granulomatosis (WG), sarcoidosis, psoriasis and psoriatic arthritis except Behçet's disease (BD). In this review, the issue of arterial stiffness in RA, SLE, as well as WG, psoriasis, FMF, BD, sarcoidosis, systemic sclerosis (SS) and Takayasu's arteritis (TA) is overviewed.
\end{abstract}

Keywords: Pulse wave velocity, Arterial distensibility, Inflammation, Rheumatic diseases.

\section{INTRODUCTION}

Systemic immune and inflammatory diseases, such as rheumatoid arthritis (RA) and systemic lupus erythematosus (SLE) are associated with increased morbidity and mortality $[1,2]$. Most of this increased mortality is attributable to cardiovascular events $[1,2]$. Endothelial dysfunction, characterized by reduced nitric oxide bioavailability, is an early stage in the pathogenesis of atherosclerosis. Inflammation is associated with endothelial dysfunction and atherosclerosis [3]. Damage to the arterial wall due to atherosclerosis causes increased arterial stiffness. Atherosclerosis and its effects on the arterial system may be measured noninvasively by some techniques $[4,5]$. One such technique, pulse wave velocity (PWV), which is defined as arterial pulse's velocity of moving along vessel wall, as an indicator of arterial distensibility, plays an important clinical role in describing patients under high cardiovascular risk and serebrovascular risk [4]. PWV is inversely correlated with arterial distensibility and relative arterial compliance. Theoretically, the wave velocity $(\mathrm{C} 0)$, in a thin-walled, uniform, elastic vessel containing an incompressible, inviscous fluid, with no reflections, can be expressed by the Moens-Korteweg equation [6,7]: $\mathrm{C} 0=$ $\sqrt{ } \mathrm{Eh} / 2 \rho \mathrm{R}$ (E: Young's modulus of elasticity, h: wall thickness, R: mean radius, $\rho$ : blood density). Following Bramwell and Hill [8], equation of Moens-Korteweg also can be expressed as $\mathrm{C} 0=\sqrt{\mathrm{dP}} \mathrm{V} / \mathrm{dV} \rho(\mathrm{P}$ : pressure, $\mathrm{V}$ : volume of tube per unit length, $\mathrm{dV} / \mathrm{VdP}$ : volume compliance of the tube). In this equation, the square of the wave velocity is

*Address correspondence to this author at the Department of Cardiology, Kartal Kosuyolu Yuksek Ihtisas Educational and Research Hospital (Kosuyolu Heart Hospital), Istanbul Turkey; Tel: +90 (216) 45944 40; Fax: +90 (216) 45963 21; E-mail: mustafayilldiz@yahoo.com associated with the inverse of the volume compliance that represents the total arterial stiffness.

Arterial stiffness increases in accelerated atherosclerosis due to inflammation [9]. Large artery stiffness is recognized as a modifiable, independent predictor of cardiovascular risk [10]. Structural components within the arterial wall, mainly collagen and elastin, together with transmural pressure, are key determinants of large arterial PWV. Arterial stiffness can be affected by both structural and functional changes [11]. Structural changes involve the composition of the arterial wall, hypertrophy of smooth muscle cell and decrease in contents of extracellular matrix [12]. Endothelial dysfunction leads to a number of changes in the extracellular matrix including smooth muscle cell proliferation and increased synthesis of structural proteins including collagen [13, 14]. An increase in circulating inflammatory mediators promotes white cell infiltration into arteries, and a change in vascular smooth muscle phenotype. Both these cell types release the matrix metalloproteinases that can degrade elastin. Decrease of elastin from the media could be expected to result in arterial stiffening. Under inflammatory conditions, vascular smooth muscle cells also express osteoblast markers and can take up phosphate to produce bioapatite, leading to medial calcification and reduced arterial distensibility. Perivascular inflammation and cellular infiltration around the vasa vasorum may lead to vessel ischemia, which may also promote matrix remodeling and eventually stiffening of the arteries. The increase in aortic stiffness may increase the impedance to left ventricular ejection and then reduce the effective coronary blood flow: The arterial pressure waveform is a composite of the forward pressure wave created by ventricular contraction and a reflected wave. In elastic vessels such as aorta, the reflected wave tends to arrive back 
at the aortic root during diastole, serving to augment diastolic blood pressure and therefore, improve coronary artery perfusion [15]. In the case of stiff arteries the reflected wave arrives back at the central arteries earlier, causing augmentation of the systolic blood pressure. High central systolic blood pressure causes the development of left ventricular hypertrophy and finally reduces coronary artery perfusion [15].

Arteries become wider and less elastic (increased PWV) with advancing age as a consequence of the age-related reduction in arterial elastin and increase in collagen content [16]. Stiffness becomes higher at high blood pressure and lower at low blood pressure, through mechanical change in arterial wall stretching and resulting change in contribution of elastin and collagen fibers to the elastic modulus $[17,18]$. However, smooth muscle tone also influences the stiffness of elastic and muscular arteries, suggesting functional regulation of stiffness by local and/or circulating vasoactive substances such as endothelial derived nitric oxide [19-22]. This may explain why traditional risk factors such as hypercholesterolemia and diabetes mellitus, which are known to cause endothelial dysfunction characterized by reduced nitric oxide bioavailability, are also associated with increased arterial stiffness.

Systemic inflammation has been associated with endothelial dysfunction [23]. The circulating inflammation mediators such as $\mathrm{C}$ reactive protein (CRP) and cytokines can directly alter endothelial nitric oxide bioavailability. The degree of inflammation, as assessed by high sensitivity CRP, cytokines or antineutrophil cytoplasmic antibodies $(\boldsymbol{A N C A})$ also predicts cardiovascular mortality and morbidity [1]. These observations suggest that arterial stiffness and cardiovascular mortality and morbidity should be increased in subjects with systemic inflammation [24-34]. However, some data concerning this are conflicting [35]. We and others have demonstrated an increase in the carotid-femoral (aortic) PWV that is a technique in which large artery elasticity is assessed from analysis of the peripheral arterial waveform [4], in patients with chronic inflammatory conditions such as RA, SLE, FMF, WG, sarcoidosis, psoriasis and psoriatic arthritis.

\section{The Carotid-Femoral (Aortic) PWV Measurement in Different Inflammatory Disorders}

In our study arterial stiffness was assessed by automatic carotid-femoral (aortic) PWV measurement using the Complior Colson device (Createch Industrie, France); the technical characteristics of this device have been described, and indicate inter and intra observer repeatability coefficient values $>0.9$ [4]. The Complior system is designed to determine the arterial distensibility from the pulse wave time interval and velocity measurements. This system is made of a Complior PC board installed in an IBM APTIVA. The Complior software takes use of the computer resources for the calculation, the display and the recording of the data. Two acoustic sensors deliver the signals of the pulse wave to the acquisition board. A pedal triggers the data acquisition. The Complior kit is made of; (I) a Complior data acquisition board installed in an APTIVA IBM PC computer; the PC runs with a 486DX2 50MHz and has a 270 Mo hard drive, (II) the Complior software version 3.0 installed in the IBM PC, (III) two acoustic sensors, (IV) a trigger pedal, (V) and a Cannon BJ-200ex printer. The computer is configured for $220 \mathrm{~V} \mathrm{AC}$ main. PWV along the aorta can be measured by using two ultrasound or strain-gauge transducers [non - invasively using a TY-306 Fukuda pressure sensitive transducer (Fukuda, Tokyo, Japan)] fixed transcutaneously over the course of a pair of arteries separated by a known distance: the femoral and right common carotid arteries. During preprocessing analysis the gain of each waveform was adjusted to obtain an equal signal for the two wave forms. During PWV measurements, after pulse waveforms of sufficient quality were recorded, the digitalization process was initiated by the operator and automatic calculation of the time delay between two upstrokes was started. Measurement was repeated over 10 different cardiac cycles, and the mean value was used for the final analysis. PWV is calculated from measurements of pulse transit time and the distance (the distance between two recording sites is measured on the surface of body in meters) travelled by the pulse between two recording sites, according to the following formula:

$$
\operatorname{PWV}(\mathrm{m} / \mathrm{s})=\text { distance }(\mathrm{m}) / \text { transit time }(\mathrm{s})
$$

\section{RA}

RA is a systemic immune and inflammatory disease associated with accelerated atherosclerosis and excess cardiovascular morbidity and mortality $[1,36]$. This inflammation may act to impair endothelial function, arterial compliance and arterial elasticity and as a contributing factor in the initiation or the progression of atherosclerosis. Some studies showed that arterial elasticity is reduced in patients with RA $[37,38]$. Recently, we also found that carotid-femoral PWV $(8.29 \pm 0.64 \mathrm{~m} / \mathrm{s}$ vs $7.52 \pm 0.63 \mathrm{~m} / \mathrm{s})$ is increased, arterial elasticity is decreased, in young patients with RA (21-34 years old, 7 women, mean RA duration: 13.8 \pm 12.6 months), as compared with control $(\mathrm{p}=0.03)$ [27]. In the young patients with RA pulse wave propagation time (it is inversely related to the arterial PWV to the classical formula "PWV (m/s)=Distance $(\mathrm{m}) /$ Transit time (s)") between measurement sites was significantly shorter than in the control group $(\mathrm{p}=0.02)[27]$.

\section{SLE}

SLE is a chronic inflammatory autoimmune disease affecting young women associated with increased atherosclerotic vascular diseases [39]. In SLE, the degree of systemic inflammation correlates with development of atherosclerosis [40]. Antiphospholipid antibodies (aPL) (a family of autoantibodies that recognize various combinations of phospholipids and phospholipid-binding proteins) and immune complexes occur more commonly in patients with SLE [41]. In SLE, although Farzaneh-Far et al. [42] suggest that aPL are not associated with increased preclinical or clinical atherosclerosis and arterial stiffening, these antibodies may be a cause of arterial damage which initiates atherogenesis [39]. These complexes bind to receptors on the endothelium, triggering an upregulation of adhesion molecules such as E-selectin, intercellular adhesion molecules 1 (ICAM-1) and vascular cell adhesion molecules 1 (VCAM-1). Also, oxidized low density lipoprotein (LDL), lipoprotein (a) and CD40-CD40L have role in the pathogenesis of atherosclerosis, thrombosis and inflammatory processes [43-46]. 
Recently, we found that carotid-femoral (aortic) PWV (8.98 $\pm 2.05 \mathrm{~m} / \mathrm{s}$ vs $8.05 \pm 0.94 \mathrm{~m} / \mathrm{s}$ ) is increased in premenopausal women with SLE (mean age: $33.6 \pm 9.6$ vs $30.2 \pm 9.2$ years old, 24 women, mean SLE duration: $5.3 \pm 4.6$ years), as compared with control $(\mathrm{p}=0.04)$ [28]. Aortic PWV was determined by using an automatic device, the Complior Colson (France), which allowed on-line pulse wave recording and automatic calculation of PWV.

\section{WG}

WG is a rare disease, affecting only 1 in every 30.000 50.000 people, that often begins with inflammation of the upper airways or lungs and may progress to an inflammation of blood vessels throughout the body [47-51]. There is a strong and specific association of WG with presence of antineutrophil cytoplasmic antibodies (ANCA) to a defined target antigen, proteinase 3 (PR3-ANCA), which is present within primary azurophil granules of neutrophils and lysozymes of monocytes [48]. Upon cytokine priming of neutrophils, this enzyme translocates to the cell surface, where PR3-ANCAs can interact with their antigens and activate neutrophils [49]. The presence of ANCA in the plasma of patients and genetic involvement of the human leukocyte antigen system reflects an autoimmune background of the disease. de Leeuw et al. [52] demonstrated that atherosclerosis, a systemic inflammatory disease, as determined by carotid intima-media thickness, was increased in patients with WG. Recently, we showed that carotid-femoral (aortic) $\mathrm{PWV}$ is increased in patients with WG, as compared with control $(p=0.04)$ [29].

\section{Psoriasis}

Psoriasis is a hereditary and chronic inflammatory skin disorder affecting $2-3 \%$ of the Caucasian population [53]. It is mediated by $\mathrm{T}$ cells, dendritic cells and inflammatory cytokines and characterized by marked increases in keratinocyte proliferation, prominent alterations in dermal capillary vasculature [54]. Psoriatic arthritis has been defined as an inflammatory arthritis associated with psoriasis, usually seronegative for rheumatoid factor. Psoriatic arthritis affects men and women almost equally. The prevalence of Psoriatic arthritis among patients with psoriasis has varied from $6 \%$ to $42 \%$ [55]. It is demonstrated that psoriasis and psoriatic arthritis appear to be associated with an increased cardiovascular mortality and morbidity [56]. We and others have demonstrated an increase in the carotid-femoral (aortic) PWV [30, 57].

\section{FMF}

FMF is an autosomal recessive disorder virtually restricted to certain ethnic groups originating from the Middle East: Sephardic Jews, Armenians, Arabs, Druze and Turks [58]. It is characterized by recurrent episodes of serosal inflammation, chest pain, and arthritis usually accompanied by fever [58]. The main complication of untreated patients is the development of amyloidosis [58]. In most FMF patients, colchicine treatment prevents febrile attacks and development of amyloidosis [59]. During the febrile attacks, an acute phase response develop, manifested by a marked increase in erythrocyte sedimentation rate (ESR), CRP, serum amyloid A, fibrinogen and leucocytes [58]. Histopathologic examination of FMF involves inflammation with infiltration by neutrophils [58]. In our study, the carotidfemoral PWV $(8.53 \pm 1.65 \mathrm{~m} / \mathrm{s}$ vs $7.75 \pm 0.86 \mathrm{~m} / \mathrm{s})$ is slightly increased in patients with FMF which compared with control group $(\mathrm{p}=0.05)[31,32]$. We found significant correlation between PWV and age $(\mathrm{p}<0.001, \mathrm{r}=0.67)$, body mass index $(\mathrm{p}<0.001, \mathrm{r}=0.52)$ and leukocytes $(\mathrm{p}<0.001, \mathrm{r}=0.66)$ in all groups and in patients with FMF group $(\mathrm{p}<0.001, \mathrm{r}=0.73$; $\mathrm{p}=0.01, \mathrm{r}=0.52 ; \mathrm{p}<0.001, \mathrm{r}=0.69$, respectively).

We found significant correlation between PWV and leukocytes. FMF is an autosomal recessive disorder characterized by mutations in the MEFV gene located on 16p [60]. The gene encodes a 781-amino acid protein called pyrin expressed in cells of the myeloid lineage. Although the role of MEFV gene in the development of FMF attacks does not yet known clearly, its malfunction results eventually in inflammation. And it has been proposed that in FMF any minor stimulus leads to an uncontrolled inflammatory reaction with complement activation, due to absence of an inhibitor of C5a and excessive tumor necrosis factor (TNF) release $[61,62]$. The inflammatory process of FMF is also caused by leukotriene B4, a potent lipid chemoattractant and mediator of acute inflammation [63]. Circulating leucocytes play important roles in atherosclerosis which is an inflammatory disease [64]. Positive associations between total leukocyte count and risk factors of atherosclerosis or coronary artery diseases are frequently mentioned $[65,66]$.

\section{Sarcoidosis}

Sarcoidosis is a systemic inflammatory multiorgan disease, characterized in the affected organs by T-lymphocytemononuclear phagocyte infiltration, granuloma formation, and distortion of normal microarchitecture. Histology of granulomas shows a central zone with macrophages, epithelioid cells, and multinucleated giant cells in addition to activated CD4 lymphocytes, and a peripheral zone with macrophages, fibroblasts, CD4 and CD8 lymphocytes [67-71]. The reported prevalence of sarcoidosis varies from 9 to 64 per 100.000 populations (in Sweden and in Italy, respectively) [68]. Although, sarcoidosis is known to be a systemic inflammatory disease which can affect virtually any organ system, it unusually complicates vascular involvement. However in fact, several authors have suggested that vasculitis may be a feature of sarcoidosis; but, such reports usually related to cutaneous vasculitis $[3,4]$. In a one study, granulomatous angiitis and microangiopathy were reported in $30.8 \%$ of sarcoidosis patients with cutaneous involvement [69]. On the other hand, reports on the coexistence of sarcoidosis and vasculitis had led us to think the possibility that sarcoidosis and vasculitis may be etiopathgenetically related. This inflammation of sarcoidosis may act to impair endothelial function, arterial compliance and arterial elasticity and as a contributing factor in the initiation or the progression of atherosclerosis. Recently, we demonstrated that the carotidfemoral (aortic) PWV (10.04 \pm 1.73 vs $9.05 \pm 1.18 \mathrm{~m} / \mathrm{s})$ was higher in patients with sarcoidosis (12 women, 7 man, sarcoidosis duration: $124.8 \pm 85.9$ months) than in control subjects $(\mathrm{p}=0.04)[33]$.

\section{BD}

BD is a chronic, multisystem disorder characterized by genital and oral aphtae, skin lesions and uveitis [72]. In some 
patients, manifestations of vascular complications, which may include deep vein and arterial thrombosis, aortic and arterial aneurysm, may dominate the clinical picture [72]. The cause of vascular disease in BD is unknown. Histopathologic studies have demonstrated that the predominant lesion is vasculitis. The vessel wall and perivascular tissue are infiltrated by lymphocytes, monocytes, plasma cells and neutrophils [72]. Recent studies suggest that activated leukocytes may contribute to vascular injury in $\mathrm{BD}$ [73]. In vivo, neutrophils from patients with BD generate high levels of oxygen derived free radicals and cause endothelial cell lysis [73]. Concentrations of circulating lipid peroxidation products are elevated in patients with BD [74]. Orem et al. [75] studied plasma lipoprotein (a) and its relationship with disease activity in patients with BD. They concluded that the fluctuations of plasma lipoprotein levels with the activity of disease may be a contributing risk factor in the development of thrombogenic complications in patients with BD. Other study showed that the levels of autoantibodies against oxidized LDL were significantly higher in patients than controls [76]. These autoantibodies may be a factor responsible for endothelial dysfunction and development of vascular pathology in BD [76]. Lipid peroxidation was found increased in the active period compared to the inactive period of $\mathrm{BD}$. Therefore, patients with active BD may be much more susceptible to the atherogenic events than those in the inactive period of the disease and control subjects. We studied 14 patients with BD (18-44 years old, 10 men) and 28 healthy subjects (18-39 years old, 21 men) without known cardiovascular disease. Arterial distensibility was assessed by automatic carotid-femoral PWV measurement using the Complior Colson device. The carotid-femoral PWV (8.4 \pm 1.4 vs $8.5 \pm 1.1 \mathrm{~m} / \mathrm{s})$ is not increased in patients with BD compared with control subjects $(p>0.05)$ [35]. This finding may explain the decrease of mortality rate within time in patients with BD. In contrast to our study Chang et al. [77] showed that patients with BD had significantly higher PWV values than in controls.

\section{SS}

SS is a clinically heterogeneous generalized disorder which affects the connective tissue of the skin and internal organs such as gastrointestinal tract, lungs, heart and kidneys. It is characterized by alterations of the microvasculature, disturbances of the immune system and by massive deposition of collagen [78]. Endothelial dysfunction and vasculopathy of the small and large vessels are crucial pathogenic factors in SS. Timár et al. [79] showed that increased augmentation index, is used as clinical measurements of arterial stiffness, and PWV of the aorta in comparison to age and sex matched healthy controls in patients with SS. Cypiene et al. [80] also demonstrated that SS patients have increased augmentation index and PWV and lower flow-mediated dilatation (is an ultrasound-based technique that measures nitric oxide mediated vasodilatation of the brachial artery in response to increased arterial wall shear stress) as compared to control subjects.

\section{TA}

TA is a rare, chronic, inflammatory disease primarily of the aorta and its branches [81, 82]. The subclavian, renal and carotid arteries can also be involved. Inflammation of large blood vessels may cause segments of the vessels to weaken and stretch, resulting in an aneurysm. Vessels can also become narrowed or even completely blocked. TA is more common in women than in men and usually begins in the $2^{\text {nd }}$ or $3^{\text {rd }}$ decade [82]. The diagnosis of TA is based on a combination of factors, including angiography, computed axial tomography and magnetic resonance imaging. Cardiovascular disease is a major cause of mortality and morbidity in patients with TA. $\mathrm{Ng}$ et al. [83] demonstrated that the mean carotid-femoral PWV $(\mathrm{p}=0.03)$, aortic augmentation index derived from the radial artery $(\mathrm{p}=0.002)$ and carotid augmentation index $(p=0.03)$ were higher in patients with TA compared with controls.

In conclusion, the arterial distensibility was assessed by automatic carotid-femoral (aortic) PWV measurement using the Complior Colson device was decreased in chronic inflammatory rheumatic diseases. Decrease of arterial distensibility in chronic inflammatory rheumatic diseases are especially due to inflammation that is triggered by cardiovascular risk factors such as hypertension, hyperlipidemia, hyperglycemia. In these disorders there is increased risk of developing premature cardiovascular disease but clear guidelines on the management of cardiovascular risk factors is still missing. As inflammation is the basic pathology in these diseases, anti-inflammatory theraphy would be the main stay treatment strategy for the protection of cardiovascular events in the near future.

\section{ABBREVIATIONS}

$\begin{array}{ll}(\mathrm{PWV}) & =\text { Pulse wave velocity } \\ (\mathrm{RA}) & =\text { Rheumatoid arthritis } \\ (\mathrm{SLE}) & =\text { Systemic lupus erythematosus } \\ (\mathrm{FMF}) & =\text { Familial Mediterranean fever } \\ (\mathrm{WG}) & =\text { Wegener's granulomatosis } \\ (\mathrm{BD}) & =\text { Behçet's disease } \\ (\mathrm{SS}) & =\text { Systemic sclerosis } \\ (\mathrm{TA}) & =\text { Takayasu's arteritis } \\ (\mathrm{CRP}) & =\text { Antineutrophil cytoplasmic antibodies } \\ (\mathrm{ANCA}) & =\text { Antiphospholipid antibodies } \\ (\mathrm{aPL}) & =\text { Vascular cell adhesion molecules } 1 \\ (\mathrm{ICAM}-1) & =\text { Low density lipoprotein } \\ (\mathrm{VCAM}-1) & =\text { Erythrocyte sedimentation rate } \\ (\mathrm{LDL}) & =\end{array}$

\section{REFERENCES}

[1] Wållberg-Jonsson S, Johansson H, Ohman ML, RantapääDahlqvist S. Extent of inflammation predicts cardiovascular disease and overall mortality in seropozitive rheumatoid arthritis: a retrospective cohort study from disease onset. J Rheumatol 1999; 26: 2562-71.

[2] Manzi S, Meilahn EN, Rairie JE, et al. Age-specific incidence rates of myocardial infarction and angina in women with systemic lupus erythematosus: comparison with the Framingham Study. Am J Epidemiol 1997; 145: 408-15. 
[3] Libby P, Ridker PM, Maseri A. Inflammation and atherosclerosis. Circulation 2002; 105: 1135-43.

[4] Asmar R, Benetos A, Topouchian J, et al. Assessment of arterial distensibility by automatic pulse wave velocity measurement: validation and clinical application studies. Hypertension 1995; 26 : 485-90.

[5] Yildiz M. Commentary on viewpoint: the human cutaneous circulation as a model of generalized microvascular function. J Appl Physiol 2008; 105: 382.

[6] Moens AI. Die Pulskurve. Leiden, E.J. Brill, 1878; p. 90.

[7] Korteweg DJ. Über die Fortpflanzungsgeschwindigkeit des Schalles in elastischen Röhren. Ann Phys Chem Neue Folge 1878; 5: 225 .

[8] Bramwell JC, Hill AV. The velocity of the pulse wave in man. Proc R Soc Lond (Biol) 1922; 93: 298-306.

[9] Wang YX, Fitch RM. Vascular stiffness: measurements, mechanisms and implications. Curr Vasc Pharmacol 2004; 2: 379-84.

[10] Laurent S, Boutouyrie P, Asmar R, et al. Aortic stiffness is an independent predictor of all-cause and cardiovascular mortality in hypertensive patients. Hypertension 2001; 37: 1236-41.

[11] Guerin AP, Blacher J, Pannier B, Marchais SJ, Safar ME, London GM. Impact of aortic stiffness attenuation on survival of patients in end-stage renal failure. Circulation 2001; 103: 987-92.

[12] Olivetti G, Anversa P, Melissari M, Loud AV. Morphometry of medial hypertrophy in the rat thoracic aorta. Lab Invest 1980; 42: 559-65.

[13] McEniery CM, Wilkinson IB. Large artery stiffness and inflammation. J Hum Hypertens 2005; 19: 507-9.

[14] Schiffrin EL. Vascular stiffening and arterial compliance: implications for systolic blood pressure. Am J Hypertens 2004; 17: 39S$48 \mathrm{~S}$.

[15] Mackenzie IS, Wilkinson IB, Cockcroft JR. Assessment of arterial stiffness in clinical practice. Q J Med 2002; 95: 67-74.

[16] Learoyd BM, Taylor MG. Alterations with age in the viscoelastic properties of human arterial walls. Circ Res 1966;18: 278-92.

[17] Armentano RL, Barra JG, Levenson J, Simon A, Pichel RH. Arterial wall mechanics in conscious dogs: assessment of viscous, intertial, and elastic moduli to characterize aortic wall behavior. Circ Res 1995; 76: 468-78.

[18] Korurek M, Yildiz M, Yüksel A. Modeling of the arterial compliance in the different stage of primary hypertension using equivalent electronic system. Atherosclerosis (Abst) 2008; 9: S235.

[19] Boutouyrie P, Bézie Y, Lacolley $\mathrm{P}$, et al. In vivo/in vitro comparison of rat abdominal aorta wall viscosity. Influence of endothelial function. Arterioscler Thromb Vasc Biol 1997; 17: 1346-55.

[20] Yildiz M, Akdemir O. Assessment of the effects of physiological release of melatonin on arterial distensibility and blood pressure. Cardiol Young 2009; 6: 1-6.

[21] Yildiz M, Sahin B, Sahin A. Acute effects of oral melatonin administration on arterial distensibility, as determined by carotidfemoral pulse wave velocity, in healthy young men. Exp Clin Cardol 2006; 11:311-3.

[22] Altun A, Erdogan O, Yildiz M. Acute effect of DDD versus VVI pacing on arterial distensibility. Cardiology 2004; 102: 89-92.

[23] Hingorani AD, Cross J, Kharbanda RK, et al. Acute systemic inflammation impairs endothelium-dependent dilatation in humans. Circulation 2000; 102: 994-9.

[24] Kaplan MJ. Management of cardiovascular disease risk in chronic inflammatory disorders. Nat Rev Rheumatol 2009; 5: 208-17.

[25] Kaplan MJ. Cardiometabolic risk in psoriasis: differential effects of biologic agents. Vasc Health Risk Manag 2008; 4: 1229-35.

[26] Gasparyan AY, Ugurlucan M. The emerging issue of cardiovascular involvement in familial Mediterranean fever. Arch Med Sci 2008; 4: 465-67.

[27] Yildiz M, Soy M, Kurum T, Ozbay G. Increased pulse wave velocity and shortened pulse wave propagation time in young patients with rheumatoid arthritis. Can J Cardiol 2004; 20: 1097100.

[28] Yildiz M, Yildiz SB, Soy M, Tutkan H. Impairment of arterial distensibility in premenopausal women with systemic lupus erythematosus. Kardiol Pol 2008; 66: 1194-9.

[29] Yildiz M, Soy M, Kürüm T, Yildiz BS. Arterial distensibility in Wegener's granulomatosis: a carotid-femoral pulse wave velocity study. Anadolu Kardiyol Derg 2007; 7: 281-5.

[30] Soy M, Yildiz M, Sevki UM, Karaca N, Güfer G, Piskin S. Susceptibility to atherosclerosis in patients with psoriasis and psoriatic arthritis as determined by carotid-femoral (aortic) pulsewave velocity measurement. Rev Esp Cardiol 2009; 62: 96-9.

[31] Yildiz M, Masatlioglu S, Seymen P, Aytac E, Sahin B, Seymen HO. The carotid-femoral (aortic) pulse wave velocity as a marker of arterial stiffness in familial Mediterranean fever. Can J Cardiol 2006; 22: 1127-31.

[32] Yildiz M, Biteker M, Ozkan M. Assessment of aortic stiffness and ventricular functions in familial Mediterranean fever. Anadolu Kardiyol Derg 2008; 8: 395.

[33] Balci H, Sipahi DS, Yildiz M, Metin G, Simse KG. The evaluation of the relationship between the inflammatory markers and arterial distensibility in patients with sarcoidosis. Trakya Üniversitesi Tip Fakültesi Dergisi 2010 (in press).

[34] Yildiz M, Altun A, Ozbay G. Assessment of arterial distensibility in patients with cardiac syndrome X. Angiology 2007; 58: 458-62.

[35] Kurum T, Yildiz M, Soy M, Ozbay G, Alimgil L, Tüzün B. Arterial distensibility as determined by carotid-femoral pulse wave velocity in patients with Behçet's disease. Clin Rheumatol 2005; 24: 1348.

[36] Ridker PM. High-sensitivity C-reactive protein: potential adjunct for global risk assessment in the primary prevention of cardiovascular disease. Circulation 2001; 103: 1813-8.

[37] Wong M, Toh L, Wilson A, et al. Reduced arterial elasticity in rheumatoid arthritis and the relationship to vascular disease risk factors and inflammation. Arthritis Rheum 2003; 48: 81-9.

[38] Van Doornum S, McColl G, Jenkins A, Green DJ, Wicks IP. Screening for atherosclerosis in patients with rheumatoid arthritis: comparison of two in vivo tests of vascular function. Arthritis Rheum 2003; 48: 72-80.

[39] Selzer F, Sutton-Tyrrell K, Fitzgerald S, Tracy R, Kuller L, Manzi $\mathrm{S}$. Vascular stiffness in women with systemic lupus erythematosus. Hypertension 2001; 37: 1075-82.

[40] Hahn BH. Systemic lupus erythematosus and accelerated atherosclerosis. N Engl J Med 2003; 349: 2379-80.

[41] Petri M. Epidemiology of the antiphospholipid antibody syndrome. J Autoimmun 2000; 15: 145-51.

[42] Farzaneh-Far A, Roman MJ, Lockshin MD, et al. Relationship of antiphospholipid antibodies to cardiovascular manifestations of systemic lupus erythematosus. Arthritis Rheum 2006; 54: 391825.

[43] Manzi S, Wasko MC. Inflammation-mediated rheumatic diseases and atherosclerosis. Ann Rheum Dis 2000; 59: 321-5.

[44] Tsimakis S, Brilakis ES, Miller ER, et al. Oxidized phospholipids, Lp(a) lipoprotein, and coronary artery disease. N Engl J Med 2005; 353: 46-57.

[45] Wityk RJ, Kittner SJ, Jenner JL, et al. Lipoprotein (a) and the risk of ischemic stroke in young women. Atherosclerosis 2000; 150: 389-96.

[46] Henn V, Slupsky JR, Gräfe M, et al. CD40 ligand on activated platelets triggers an inflammatory reaction of endothelial cells. Nature 1998; 391: 591-4.

[47] Lamprecht P, Gross WL. Wegener's granulomatosis. Herz 2004; 29: 47-56.

[48] Csernok E, Muller A, Gross WL. Immunopathology of ANCAassociated vasculitis. Intern Med 1999; 38: 759-65.

[49] Csernok E, Ernst M, Schmitt W, Bainton DF, Gross WL. Activated neutrophils express proteinase 3 on their plasma membrane in vitro and in vivo.Clin Exp Immunol 1994; 95: 244-50.

[50] Jagiello P, Gencik M, Arning L, et al. New genomic region for Wegener's granulomatosis as revealed by an extended association screen with 202 apoptosis-related genes. Hum Genet 2004; 114 : 468-77.

[51] Reumaux D, Duthilleul P, Roos D. Pathogenesis of disease associated with antineutrophil cytoplasmic autoantibodies. Hum Immunol 2004; 65: 1-12.

[52] de Leeuw K, Sanders J-S, Stegeman C, Smit A, Kallenberg CG, Bijl M. Accelerated atherosclerosis in patients with Wegener's granulomatosis. Ann Rheum Dis 2005; 64: 753-9.

[53] Myers W, Opeola M, Gottlieb AB. Common clinical features and disease mechanisms of psoriasis and psoriatic arthritis. Curr Rheumatol Rep 2004; 6: 306-13.

[54] Gaspari AA. Innate and adaptive immunity and the pathophysiology of psoriasis. J Am Acad Dermatol 2006; 54 (3 Suppl 2): S6780 .

[55] Scarpa R, Oriente P, Pucino A, et al. Psoriatic arthritis in psoriatic patients. Br J Rheumatol 1984: 23: 246-50. 
[56] Peters MJ, van der Horst-Bruinsma IE, Dijkmans BA, Nurmohamed MT. Cardiovascular risk profile of patients with spondylarthropathies, particularly ankylosing spondylitis and psoriatic arthritis. Semin Arthritis Rheum 2004; 34: 585-92.

[57] Gisondi P, Fantin F, Del Giglio M, et al. Chronic plaque psoriasis is associated with increased arterial stiffness. Dermatology 2009; 218: 110-3.

[58] Sohar E, Gafni J, Pras M, Heller H. Familial Mediterranean fever: a survey of 470 cases and review of the literature. Am J Med 1967; 43: 227-53.

[59] Zemer D, Pras M, Sohar E, Modan M, Cabili S, Gafni J. Colchicine in the prevention and treatment of the familial Mediterranean fever. N Engl J Med 1986; 314: 1001-5.

[60] Pras E, Aksentijevich I, Gruberg L, et al. Mapping of a gene causing familial Mediterranean fever to the short arm of chromosome 16. N Engl J Med 1992; 326: 1509-13.

[61] Ayesh SK, Ferne M, Flechner I, Babior BM, Matzner Y. Partial characterization of a C5a-inhibitor in peritoneal fluid. J Immunol 1990; 144: 3066-70.

[62] Schatner A, Lachmi M, Livneh A, Pras M, Hahn T. Tumor necrosis factor in familial Mediterranean fever. Am J Med 1991; 90: 434-8.

[63] Smith MJ, Ford-Hutchinson AW, Bray MA. Leukotriene B: a potential mediator of inflammation. J Pharm Pharmacol 1980; 32: 517-8.

[64] Huang ZS, Jeng JS, Wang CH, Yip PK, Wu TH, Lee TK. Correlations between peripheral differential leukocyte counts and carotid atherosclerosis in non-smokers. Atherosclerosis 2001; 158: 431-6.

[65] Nieto FJ, Szklo M, Folsom AR, Rock R, Mercuri M. Leukocyte count correlates in middle-aged adults: the atherosclerosis risk in communities (ARIC) Study. Am J Epidemiol 1992; 136: 525-37.

[66] Weijenberg MP, Feskens EJ, Kromhout D. White blood cell count and the risk of coronary heart disease and all-cause mortality in elderly men. Arterioscler Thromb Vasc Biol 1996; 16: 499-503.

[67] Scadding JG, Mitchell DN. Sarcoidosis. 2nd ed. Chapman \& Hall: London 1985.

[68] Müller-Quernheim J. Sarcoidosis: immunopathogenetic concepts and their clinical application. Eur Respir J 1998; 12: 716-38.

[69] Takemura T, Shishiba T, Akiyama O, Oritsu M, Matsui Y, Eishi Y. Vascular involvement in cutaneous sarcoidosis. Pathol Int 1997; 47: 84-9.
[70] Gran JT. Multiorgan sarcoidosis presenting with symmetric polyarthralgia, cutaneous vasculitis, and sicca symptoms. Scand J Rheumatol 1997; 26: 225-6.

[71] Muscari A, Nanni Costa A, Bozzoli C, et al. Immunologic changes in circulating leukocytes in presence of atherosclerotic disease. Recent Prog Med 1994; 85: 66-73.

[72] Sakane T, Takeno M, Suzuki N, Inaba G. Behçet's disease. N Engl J Med 1999; 341: 1284-91.

[73] Niwa Y, Miyake S, Sakane T, Shingu M, Yokoyama M. Autooxidative damage in Behçet's disease - endothelial cell damage following the elevated oxygen radicals generated by stimulated neutrophils. Clin Exp Immunol 1982; 49: 247-55.

[74] Freitas JP, Filipe P, Yousefi A, Emerit I, Guerra Rodrigo F. Oxidative stress in Adamantiades-Behçet's disease. Dermatology 1998; 197: 343-8.

[75] Orem A, Deger O, Cimsit G, Karahan SC, Akyol N, Yildirmis S. Plasma lipoprotein (a) and its relationship with disease activity in patients with Behçet's disease. Eur J Clin Chem Clin Biochem 1995; 33: 473-8.

[76] Orem A, Cimsit G, Deger O, Vanizor B, Karahan SC. Autoantibodies against modified low-density lipoprotein in patients with Behçet's disease. Dermatology 1999; 198: 243-6.

[77] Chang HK, Kim SK, Lee SS, Rhee MY. Arterial stiffness in Behcet's disease: increased regional pulse wave velocity values. Ann Rheum Dis 2006; 65: 415-6.

[78] Medsger TA, Masi AT. Epidemiology of progressive systemic sclerosis. Clin Rheum Dis 1979; 5: 15-25.

[79] Timár O, Soltész P, Szamosi S, et al. Increased arterial stiffness as the marker of vascular involvement in systemic sclerosis. J Rheumatol 2008; 35: 1329-33.

[80] Cypiene A, Laucevicius A, Venalis A, et al. The impact of systemic sclerosis on arterial wall stiffness parameters and endothelia function. Clin Rheumatol 2008; 27: 1517-22.

[81] Johnston SL, Lock RJ, Gompels MM. Takayasu arteritis: a review. J Clin Pathol 2002; 55: 481-6.

[82] Arend WP, Michel BA, Bloch DA. The American College of Rheumatology 1990 criteria for the classification of Takayasu's arteritis. Arthritis Rheum 1990; 33: 1129-34.

[83] Ng WF, Fantin F, Ng C, et al. Takayasu's arteritis: a cause of prolonged arterial stiffness. Rheumatology (Oxford) 2006; 45: 7415. 